\title{
La concepción antropológica en Orígenes de Alejandría: preexistencia del alma y su vinculación con la apocatástasis
}

\author{
Anthropological Conception of the Pre- \\ Existence of the Soul and its Connection \\ with Apocatastasis in Origen of Alexandria
}

\author{
GABRIELA CARAM \\ UNIVERSIDAD NACIONAL DE CUYO
}

Recibido: 10/05/2020 Aceptado:07/05/2020

\begin{abstract}
RESUMEN
Orígenes de Alejandría fue un importante referente de la Iglesia oriental, destacado por su enorme saber. Se lo ubica y valora como el primer exégeta que hizo obra científica y como uno de los más grandes pensadores del cristianismo antiguo, ya que en todos los dominios fue capaz de marcar un momento decisivo para el pensamiento contemporáneo suyo y posterior. Maestro de Alejandría y de Cesarea, realizó la primera gran síntesis de teología especulativa y conocimiento de la realidad.En sus reflexiones, fue amplio en la introducción de elementos de la sabiduría de otras tradiciones, entre las que se cuentan la cristiana y judía, así como también la griega y bárbara. Todas estas tradiciones espirituales han coincidido en la afirmación de que el alma humana vive y persiste después de separarse del cuerpo, constituyéndose -nuevamente, según el alejandrino- en un cuerpo etéreo que abandona el cuerpo material. De este modo, alega la supervivencia del alma a la muerte física y la posibilidad de desplazarse en diferentes dimensiones o planos. En este caso, nos detendremos en estudiar, a partir de ciertos pasajes de su obra, aquellos contenidos que posibilitan la comprensión de los tópicos fundamentales
\end{abstract}


para nuestra investigación en torno a los elementos antropológicos que aporta en sus trabajos, vinculados con la restauración final o apocatástasis.

\title{
PALABRAS CLAVE
}

ORÍGENES DE ALEJANDRÍA, PREEXISTENCIA, RESTAURACIÓN UNIVERSAL, ANTROPOLOGÍA EN ORÍGENES DE ALEJANDRÍA

\begin{abstract}
Origen of Alexandria was one of the most important figures of Eastern Church, renowned for his vast knowledge. He is considered and valued as the first exegeteto perform scientific work and as one of the greatest thinkers of ancient Christianity, since he markeda decisive moment in every field for contemporary and later thought. In addition to being a teacherin Alexandria and Caesarea, hemade the first great summary on speculative theology and knowledge of reality. In his reflections, he was able to introduce elements of the knowledge belonging to other traditions, such as Christian and Jewish, as well as Greek and Barbarian. All these spiritual traditions coincide on claiming that the human soul lives and persists after being separated from the body as an ethereal body that abandons its material counterpart, according to the alexandrine. Hence, he claims that the soul continues to live after physical death and that there is a possibility to move among different dimensions or planes.

In this case, we will study in detail, from certain passages of his work, those contents that allow us to understand the essential subjects for our investigation regarding the anthropological elements presented in his works, connected to the final restoration or apocatástasis.

KEYWORDS

ORIGEN OF ALEXANDRIA, PRE-EXISTENCE, UNIVERSAL RESTORATION, ANTHROPOLOGY IN ORIGEN OF ALEXANDRIA
\end{abstract}

\section{INTRODUCCIÓN}

ORÍGENES DE ALEJANDRÍA ${ }^{1}$ fue un pensador griego de los siglos II y III de nuestra era (Alejandría 185 - Tiro o Cesarea Marítima, 254), y considerado un referente de la Iglesia oriental, destacado por su enorme saber y por su amplia labor exegética. Se lo ubica como el primer exégeta que hizo obra científica. ${ }^{2}$

Orígenes mantuvo un diálogo permanente con los autores paganos y judíos. Abrió nuevos caminos con un lenguaje que era asequible a la mentalidad

1 La bibliografía sobre Orígenes es numerosa. Se puede consultar: H. Crouzel, Orígenes, un teólogo controvertido. Madrid: BAC, 1998, J. Daniélou, Origène. Paris: Éditions de la Table Ronde, 1948, entre otros.

2 Cf. H. de Lubac, Histoire et esprit. L'intelligencie de l'ècriture d'après Origène. Paris: Aubier, 1950,

p. 62. 
pagana, judía y cristiana, ${ }^{3}$ por lo cual la recepción de sus textos fue realizada desde múltiples cosmovisiones, apoyada en la sencillez impresa en su obra. ${ }^{4}$

El estudio y el conocimiento de Orígenes han progresado notablemente en el curso de las últimas décadas, por la importancia e incidencia del contenido de sus tesis. ${ }^{5}$ La amplitud de criterio que tuvo en utilizar para sus estudios la riqueza de varias tradiciones, distinguiendo las coordenadas fundantes de cada una de ellas, ${ }^{6}$ ha suscitado un interés peculiar ya que se trata de la obra de un exégeta, un espiritual, en la que han desempeñado un papel muy importante la filosofía, la filología y varias ciencias, entre ellas la cosmología. ${ }^{7}$

Maestro de Alejandría y de Cesarea, realizó la primera gran síntesis de teología especulativa al servicio del conocimiento de la realidad. A pesar del estricto método exegético que había desarrollado y la profundidad de sus investigaciones, Orígenes encontró rápidamente quienes discutieran sus tesis, debido a la problematicidad de ciertos temas, como la preexistencia de las almas y el retorno y restauración universal en el final de todos los seres hacia la unidad, la llamada apocatástasis. ${ }^{8}$ El alejandrino había pensado en esta noción, que atraviesa todos los géneros de la producción literaria origeniana, como una reconciliación en el momento del fin último de los tiempos, entre la providencia divina y la libertad de las criaturas. $^{9}$

Por lo que sabemos, el obispo de Alejandría Demetrio impuso a Orígenes una condena partir de la decisión del clero egipcio y aprobada por Roma en 232. Ésta, empero, fue aplicada sólo con un propósito disciplinario; se puede suponer razonablemente que el obispo fue alentado a proceder en detrimento del célebre maestro. La condena del alejandrino a raíz de sus tesis, lo obligó a mudarse a Cesarea en Palestina. Este hecho, sin embargo, no condujo necesariamente al rechazo de sus principios exegéticos y doctrinales por parte de la escuela de Alejandría. ${ }^{10}$ En efecto, los temas desarrollados por él, que se

3 Cf. J. M. Blazquez Martinez, «Orígenes y su legado al Mundo Antiguo y al Mundo Moderno», Gerión 27/1 (2009) p. 265.

$4 \mathrm{Cf}$. I. Ramelli, The Christian Doctrine of Apokatastasis: A Critical Assessment from the New Testament to Eriugena. Leiden-Boston: Brill, 2013.

5 Destacamos especialmente los trabajos de H. Crouzel, H. de Lubac, J. Daniélou, R.P.C. Hanson y M. Harl.

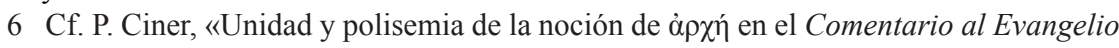
de Juan de Orígenes», Teología y Vida 52/4 (2011) p. 95.

7 H. Crouzel, Origène. Paris: Éditions Lethielleux, 1984, pp. 83-84.

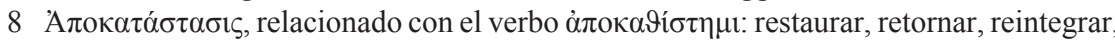
con lo cual adquiere el significado de restauración, reintegración, restitución.

9 Cf. I. Ramelli, The Christian Doctrine of Apokatastasis, 2013.

10 Cf. M Simonetti, «La controversia origeniana: caratteri e significato», Augustinianum 26 (1986) p. 8. 
cuentan casi en 800 obras, constituyen un legado proverbial, que en su tiempo le valió el sobrenombre de Adamantius (hombre de acero), y cuyos estudios se han multiplicado en los últimos años. La calidad del intérprete de la revelación bíblica y el deseo de proponer una solución racional, encuentran un equilibrio en esta gran figura.

En sus reflexiones, fue amplio en la introducción de elementos de la sabiduría de otras tradiciones, entre las que se cuentan la judía, así como también la griega y bárbara. Todas estas tradiciones espirituales, incluida la cristiana, han coincidido en la afirmación de que el alma humana vive y persiste después de separarse del cuerpo, constituyéndose-nuevamente, según el alejandrino- en un cuerpo etéreo que abandona el cuerpo material. De este modo, alega la supervivencia del alma a la muerte física, con la posibilidad de desplazarse en diferentes dimensiones o planos.

En este caso, nos detendremos a estudiar en parte de su obra aquellos elementos que consideramos de gran valor y que posibilitan la comprensión de los tópicos fundamentales para nuestra investigación. Deberemos poner nuestra atención en las nociones de principio ( $\alpha \rho \chi \eta ́)$, como concepto que abarca tanto la eternidad como el tiempo), la preexistencia, el cuerpo etéreo de la preexistencia y su transformación, para poder concebir de algún modo al hombre en su totalidad y en su trascendencia. Un inicial pasaje por la antropología origeniana permitirá ver la raíz desde donde acontece el surgimiento del núcleo de inmortalidad del hombre, que lo conducirá hacia la llamada apocatástasis.

\section{HACIA UNA NOCIÓN ANTROPOLÓGICA}

Una consideración antropológica en Orígenes requiere comprender el vínculo del hombre con Dios como su Creador, para poder arribar a una concepción correcta del ser humano. A continuación cederemos espacio a observaciones teológicas mínimas en el primer punto, necesarias para comprender el lugar de surgimiento del ser del hombre y su constitución propia.

\section{I.1. PROVIDENCIA, CREACIÓN Y MUNDO SENSIBLE}

Orígenes plantea como primer principio a la tríada Dios Padre- Hijo y

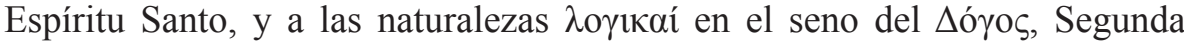
Persona de esta Trinidad, en cuyo seno son creadas. ${ }^{11}$ En De Principiis se

11 Cf. F. Batistta Harriet, «Tradición platónica acerca de los principios», Diánoia 57/68 (2012), p. 147. Sobre el análisis de la teología en Orígenes se puede consultar: S. Fernández, «La generación del lógos como solución al problema monarquiano, según Orígenes», en $\mathrm{S}$. Fernández, J. Noemi y R. Polanco (comps.), Multifariam. Homenaje a los profesores Anneliese 
menciona una bonitas divina compartida por las tres personas, cuyo principio es el Padre, pero cuya naturaleza reproducen en sí mismos tanto el Hijo como el Espíritu sin alteración, desemejanza o distancia. ${ }^{12}$ El Hijo ${ }^{13}$ es cierta imagen simétrica del Padre ( $\sigma u ́ \mu \mu \varepsilon \tau \rho o v$ cíóv $\alpha),{ }^{14}$ y esto efectivamente no implica desigualdad ontológica. Unidad y simplicidad son características de la Trinidad, aunque permanece la distinción de hipóstasis.

Asimismo, describe dos instancias de la Segunda Persona en cuanto Sabiduría- $\operatorname{Logos}^{15}$ : por un lado, en su relación sempiterna con el Padre, y por otro lado, en su volverse hacia la creación. Dentro de esta concepción, la Sabiduría o Logos, ${ }^{16}$ se entiende como un sistema de la contemplación acerca de todas las cosas y de los pensamientos; y en cuanto Logos es concebido como la comunicación de las cosas contempladas a los seres creados. ${ }^{17}$

La Sabiduría de Dios, quiso que las creaturas existieran, y decidió asumir una relación demiúrgica ( $\sigma \chi \varepsilon ́ \sigma ı v \delta \varepsilon \mu 10 v \rho \gamma \iota \kappa \eta v)^{18}$ hacia las cosas que llegarían

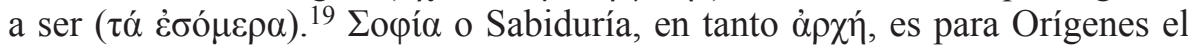

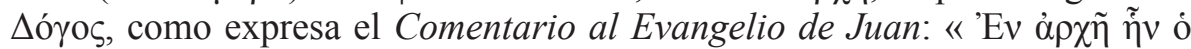

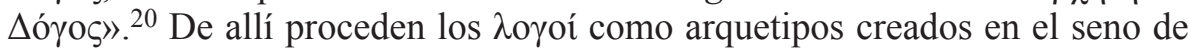

Meis, Antonio Bentué y Sergio Silva, Pontificia Universidad Católica de Chile, Santiago, 2010, pp. 193-229 (Anales de la Facultad de Teología, 1).

12 Cf. F. Batistta Harriet, «Tradición platónica acerca de los principios», p. 149.

13 En Commentaire sur Saint Jean, XIII, 25, 151-153, el Hijo es llamado Imagen (غ̇ıผ́v),

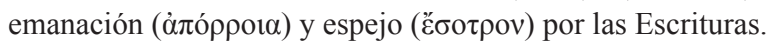

14 Orígenes de Alejandría, Contra Celsum, VI, 69.

15 Las divinas denominaciones son lo que Orígenes designa como Ė $\pi$ ívoral, que traducen perfecciones o bienes, y ocupan un desarrollo clave en su Cristología. Ellas no son simplemente

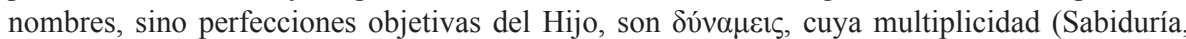
Potencia, Virtud de Dios, Vida, Resurrección, etc.) encuentra su sentido en la misión soteriológica de la Segunda Persona en relación con las creaturas. Cf. Orígenes de Alejandría, Commentaire sur Saint Jean, II, 20. Cf. también: A. Orbe, La Epinoia. Roma: Pontificia Universitas Gregoriana, 1955, pp. 17-18.

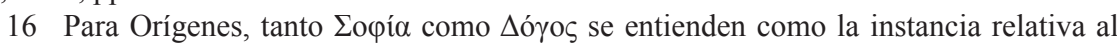

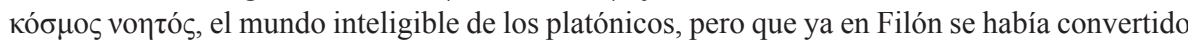
en una creación de Dios, múltiple y causante, en el seno de su $\triangle$ ó $\gamma$ os.

17 Orígenes de Alejandría, Commentaire sur Saint Jean, I, 19, 111.

18 Para la relación demiúrgica se puede ver: S. Zañartu, «Y el Logos era Dios. Comentario de Orígenes al Evangelio de Juan», Revista Teología 49/108 (2012), p. 94: «Dios es Padre de un Hijo y éste es Hijo de un Padre (10,246).Dios, que siempre ha sido sabio, es Padre del Logos por quien creó $(2,72 ; F r$ 1), de la Sabiduría que contiene los tipos de todo lo creado. En ese sentido, la creación es eterna (en la Sabiduría eterna). Por tanto, el Dios inmutable no pasó a ser creador. Dios es incognoscible $(2,172)$, estaría más allá de la esencia $(19,37)$ el Hijo, en cambio, en cuanto Sabiduría es el mundo inteligible».

19 Orígenes de Alejandría, Commentaire sur Saint Jean, Fr. 1, 5-10.

20 Orígenes de Alejandría, Commentaire sur Saint Jean, I, 19, 111. 
¿opía como en la mente de un artista, y también las realidades a las cuales

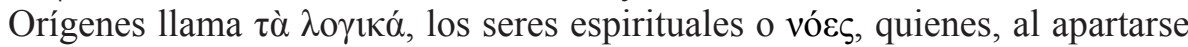
libremente de su unidad con el $\Delta$ ó $\gamma \circ \varsigma$, dieron lugar a la diferenciación en ángeles, hombres y demonios. Este apartamiento constituyó la caída original y dio la ocasión para que Dios creara el mundo sensible y el tiempo. En su juvenil De Principiis Orígenes expuso la doctrina de la caída y del origen del mundo sensible, en el cual se refiere a este tema de una manera un tanto velada, probablemente a causa de la confusión y la controversia que despertó desde el principio en su tiempo. En sus escritos, aparece claramente una distinción entre la primera creación - fuera del tiempo- de las naturalezas racionales y la segunda, que implica la diversidad ontológica y señala el inicio de la materia sensible en el espacio y el tiempo. Con respecto al hombre, distingue claramente la $\pi$ oínбıৎ de la naturaleza humana a imagen y semejanza del Creador en el primer capítulo del Génesis, y la $\pi \lambda \alpha ́ \sigma ı \varsigma$ (formación, modelación) de Adán a partir del polvo de la tierra, en el segundo capítulo. ${ }^{21}$

A partir de esta referencia relativa a la creación de almas y del mundo sensible, pretendemos aproximarnos progresivamente a lo que el padre de la Iglesia oriental ha considerado como el ser preexistente en el hombre. Para ello, consignaremos algunos elementos del dinamismo de lo humano en su realidad vincular entre cuerpo y alma, y de la manifestación de la imagen divina en su interior.

\section{I.2. El alma, el CUerpo y la imagen de Dios en el hombre}

Para arribar a la noción de preexistencia, como tema central de este estudio, se precisa una breve exposición acerca de la antropología subyacente en la cosmovisión origeniana.

En la humanidad creada, por un lado, puede distinguirse la materialidad del cuerpo, la cual es considerada por Orígenes como un principio pasivo. ${ }^{22}$ Sin embargo, en contraste con algunas corrientes mesoplatónicas y gnósticas, ha concebido a la materia como creación divina, y por lo tanto no impura

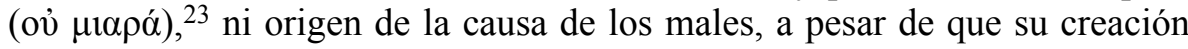
sea consecuencia de la caída, y de que en su estado presente implique necesariamente imperfección. El alejandrino destaca que Dios no deja librada la realidad material a su suerte, sino que Él mismo actúa permanentemente sobre el mundo a través del $\Delta$ ó $\gamma$ o $\varsigma$ divino y sus potencias, como un principio

21 Cf. F. Batistta Harriet, «Tradición platónica acerca de los principios», p. 159.

22 Considerar el cuerpo humano como principio pasivo demuestra la influencia de los antecedentes platónicos y estoicos de su pensamiento.

23 Orígenes de Alejandría, Contra Celso, III, 42. 
que cualifica, divide, y determina el sustrato material. Él impone el número y la medida de todas las cosas, y es la medida de la materia corporal. ${ }^{24}$

Por otra parte, aunque Orígenes no escribió un tratado sistemático sobre el alma, comienza con una definición de la misma que se aplica a todos los animales, y que implica la imaginación y el instinto; asevera, además, que la Escritura indica que la sangre es el alma. En animales que no tienen sangre se presenta un fluido similar o una fuente vital; asimismo, la opinión común y las Escrituras aceptan que los animales y los hombres tienen alma. San Pablo habría mostrado como inferior al alma -presente en el hombre y en otros seres vivos- en relación con el espíritu puro $(\pi v \varepsilon v \tilde{\mu} \alpha){ }^{25}$

El hombre es una unidad de cuerpo y alma. Pero para entender más su realidad, apelamos a las Sagradas Escrituras, que expresan en Génesis 1, 26: Y dijo Dios: «Hagamos al ser humano a nuestra imagen, como semejanza nuestra.... ${ }^{26}$. La pregunta que sigue a esta afirmación es: ¿dónde se encuentra esta imagen de Dios en el hombre? En Contra Celso, Orígenes manifiesta que la imagen que los hombres reciben de Dios no es la imagen del cuerpo, sino que el ser humano ha sido formado a imagen de Dios en relación con el alma. Pero: ¿consideramos al alma como una entidad espiritual anterior a la caída o posteriormente a este acontecimiento? Esta interrogación encuentra su respuesta en el apartado siguiente, en el cual se especifica la distinción entre las posibilidades de ser del alma.

Según Orígenes, se hace inconcebible que Dios asiente en el hombre y sus acciones (luego de la caída) su imagen en el cuerpo corruptible, que es la parte inferior del compuesto humano. Esto podría significar que la parte más elevada, el alma (en cuanto parte del compuesto hombre), tampoco estaría en la imagen de Dios, porque constituye una unidad con la carne. Inicialmente podrían considerarse dos posibilidades: o bien la imagen de Dios puede estar en la unidad de cuerpo y alma, o bien, la imagen solo está en el alma en cuanto entidad que existió anteriormente a la caída. La primera posibilidad es rechazada por Orígenes, ya que esto podría significar que Dios tendría alguna forma de compuesto, lo cual es imposible, dada la absoluta simplicidad divina. ${ }^{27}$ La única posibilidad es que la imagen de Dios esté relacionada con el hombre interior ( conduce a otra parte fundamental de la comprensión de la realidad humana: lo que se ha denominado como la teoría de las dos almas. Esta teoría lleva

24 Orígenes de Alejandría, De Principiis IV, 4, 8.

25 Orígenes de Alejandría, Traité des principes. Notes, p. 194, II, 8-9.

26 Nueva Biblia de Jerusalén, Desclée de Brouwer, 1998, Gen. 1, 26.

27 Cf. A. Lund Jacobsen, «Genesis 1-3 as Source for the Anthopology of Origen», Vigiliae Chistianae 62 (2008), p. 217.

28 Cf. Orígenes de Alejandría, Contra Celso, VI, 63. 
a comprender la esencia de lo humano, dada en la unidad entre el núcleo de ser como imagen divina en el hombre y su compuesto de alma y cuerpo, y presente en su camino hacia la inmortalidad.

\section{I.3. LA TEORÍA DE LAS DOS ALMAS: LA TERRENAL Y LA CELESTIAL O PREEXISTENTE}

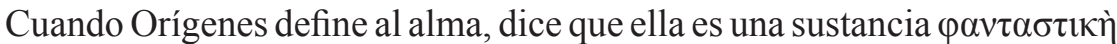

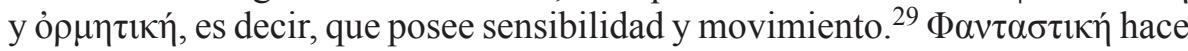
referencia a la capacidad del alma para representar realidades, es decir, designa su capacidad de emplear representaciones como paso previo al conocimiento

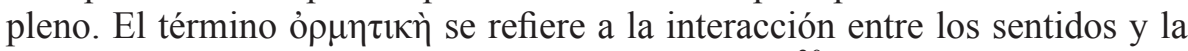
razón, que se resuelve en el movimiento voluntario. ${ }^{30}$

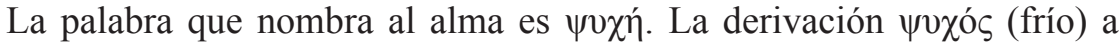

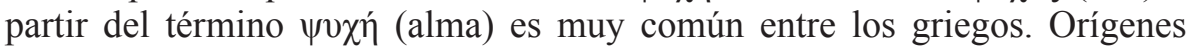
señala que el alma en la Escritura se encuentra siempre en contexto un tanto peyorativo, ya que el alma es aquella forma fría, aunque puede volver al calor. Para el alejandrino, Dios, los ángeles y los santos son fuego, pero los que se alejan de Dios se enfrían. En el seno de este pensamiento la sustancia del alma es la sangre, como aparece en De Principiis II, 8, 1, alejándose del traducianismo. ${ }^{31}$ Separa la comprensión del alma de la corporeidad pesada, es decir, la considera como una realidad no material, pero ligada al cuerpo:

El alma que llaman inferior, afirman que se sembró con el cuerpo de la semilla corporal y niegan que pueda vivir y subsistir sin el cuerpo: es por eso que a menudo la llaman carne. Esta oración de las Escrituras: La carne codicia contra el espíritu (Gá 5:17), no la entienden de la carne real, sino del alma, que es propiamente el alma de la carne. Pero intentan confirmar esto con este pasaje de Levítico: El alma de toda carne es la sangre (Lv 17:14). Ya que es la sangre vertida en toda la carne lo que le da vida, dicen que esta alma, que se llama el alma de toda carne, estaba en la sangre. ${ }^{32}$

29 Orígenes de Alejandría, De Principiis, II, 8, 1. En la versión latina: «Definitur namque

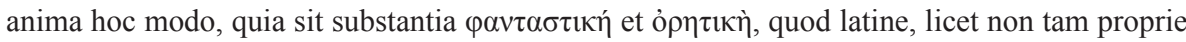
explanetur, dici tamen potest 'sensibilis et mobilis.'»

30 Cf. J. Leal, «Las dos almas de la Teología del siglo III: Tertuliano, De anima- Orígenes de Alejandría, De Principiis», Teología y Vida 55/1 (2014) pp.7-9. El autor explica que esta definición de alma tiene raíces estoicas y filonianas en Orígenes.

31 En teología se designa como traducianismo la doctrina que afirma que el alma personal de que cada ser humano se supone dotado, es resultado del acto de la generación, lo mismo que su cuerpo, derivando del alma del padre o de los padres.

32 Orígenes de Alejandría, De Principiis, III, 4, 2: «L'âme qu'ils appellent inférieure, ils affirment qu'elle a été semée avec le corps à partir de la semence corporelle et ils nient en conséquence qu'elle puisse vivre et subsister sans le corp: c'est pourquoi fréquemment ils láp- 
Existe, en cambio, lo que han llamado un alma celestial, ${ }^{33}$ que es la que se encuentra antes de la conformación de la unidad cuerpo-alma, y constituye la herencia espiritual dada por Dios a través de la imagen inscripta en ella. Esta imagen es la que está en el hombre interior, del que habla San Pablo en 2 Cor., 4, 16. De acuerdo con Orígenes, San Pablo no es el único que contempla esa concepción, sino también lo había hecho Moisés. Según expresa Lund Jacobsen: «This is clear from Gen. 1, 26 and Gen. 2, 7. For Gen. 2, 7 is not, as some believe, a repetition of Gen. 1, 26, but there ar two accounts representing different stages in the process of the Creation: Gen. 1, 26 describes the creation of immaterial man in God's image, while Gen 2, 7 describes the creation of material man from earth.» ${ }^{34}$ Sobre la distinción entre hombre interior y hombre exterior, Jacobsen señala: «It's clear, however, that according to Origen there is a fundamental distinction between the inner man created in God's image and the outer man who is not. Equally clear is the fact that Origen's interest is focused on the inner man and this path from creation to consummation. The outer man, the body, only interest Origen insofar as it plays a role for the inner man». ${ }^{35}$

Se hace claro, a partir de estos argumentos, que Orígenes comprende la creación en dos instancias, a saber: la del ser creado a imagen de Dios, esto es, el hombre interior, y la del hombre creado a partir de la tierra, como dice el Génesis 2, 7: «Entonces Yahvé formó al hombre con el polvo del suelo.» ${ }^{36}$, que supone la creación del hombre constituido en unidad de cuerpo y alma.

En Dialogus cum Heraclide se expresa abiertamente que las Sagradas Escrituras afirman que el ser humano consiste en dos «hombres»: « $\Delta$ v́o

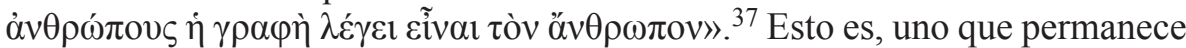
ligado a la incorruptibilidad e inmortalidad, y otro, que será alguna vez abatido por la muerte y aniquilación del cuerpo. Sin embargo, no se trata de una dualidad de tipo platónica, sino de una profunda convivencia, en la cual el hombre exterior contribuye con el camino espiritual para el que ha sido destinado este ser.

pellent la chair. Cette phrase de l'Écriture: La chair convoite contre l'esprit (Gá. 5:17), ils ne l'entendent pas de la chair proprement dite, mais de l'âme qui est à proprement parler l'âme de la chair. Mais ils essaient cependant de confirmer cela par ce passage du Lévitique: L'âme de toute chair c'est le sang (Lv. 17:14). Puisque c'est le sang répandu dans toute la chair qui lui fournit la vie, ils disent que cette âme, qui est appelée l'âme de toute chair, se trouva dans le sang.» Traducción propia.

33 Orígenes de Alejandría, De Principiis, III, 4, 2.

34 A. Lund Jacobsen, «Genesis 1-3 as Source for the Anthopology of Origen», p. 219.

35 A. Lund Jacobsen, «Genesis 1-3 as Source for the Anthopology of Origen», p.232.

36 Nueva Biblia de Jerusalén, Desclée de Brouwer, 1998, Gen. 2, 7.

37 Orígenes de Alejandría, Dialogus cum Heraclide, 15, 28-16, 4. 


\section{I.4. LA DOCTRINA DE LA PREEXISTENCIA DE LAS ALMAS}

Luego de haber distinguido las dos almas, podemos arribar a la comprensión de que el alma celestial, esto es, el hombre interior, que ha recibido la imagen de Dios, es quien conforma el estadío preexistente presente en la realidad humana, en la forma de un cuerpo etéreo.

La doctrina del cuerpo etéreo de la preexistencia y sus transformaciones fue condenada en el 553, por el Concilio de Constantinopla, pues presumiblemente la noción preexistencia no fue interpretada completamente en esta instancia en su sentido pleno. Sin embargo, continúa estando presente de algún modo, en las consideraciones de muchos, en la tradición griega platónica y en diversas tradiciones de pensamiento, perpetuándose hasta el presente. Henri Crouzel manifiesta respecto de esta tesis, que ella conforma una hipótesis central, y presente a lo largo de la línea de su teología:

Cette théorie de la préexistence, y compris celle de l'humanité du Christ, est pour Origène, suivant la ligne constante de sa théologie quand il ne s'appuie pas directement sur l'Ecriture, une hypothèse, mais une hypothèse favorite selon laquelle il pense constamment, même quand elle n'est pas explicitement mentionnée. ${ }^{38}$

Pero más que en la categoría de hipótesis, Orígenes sostuvo efectivamente la tesis de un estado preexistente de todas las inteligencias; en la preexistencia (en latín praexistentia, en griego del verbo $\pi \rho 0 \ddot{\pi} \pi \alpha ́ \rho \chi \omega,{ }^{39}$ que según A. Monaci

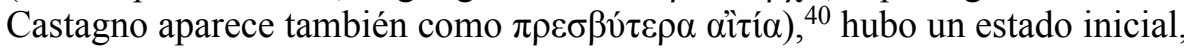
previo a la dimensión material de lo real, cuyo ser es denominado como vóec. ${ }^{41}$ Patricia Ciner muestra que la preexistencia, entendida como persistencia, continuidad y relacionalidad entre eternidad y tiempo, se presenta como una condición inherente a todas las almas y garantiza la presencia divina en todas ellas. ${ }^{42}$ Siguiendo el texto del Comentario al Evangelio de Juan II, XVIII, 129 , se menciona la necesidad de esta preexistencia:

Pues es necesario que el Logos que purifica al alma, preexista ( $\pi \rho 0 \tilde{\pi} \pi \dot{\alpha} \rho \xi 1 \alpha)$ en el alma para que luego de él y su intervención purificadora -una vez suprimida toda muerte y toda enfermedad-, la vida sin mezcla venga a quedarse en todos

38 H. Crouzel, Origène, p. 269.

39 Cf. Orígenes de Alejandría, Commentaire sur Saint Jean II, 18, 129.

40 Cf. A. Monaci Castagno, Origene. Dizionario. La cultura, il pensiero, le opere. Roma: Città Nuova, 2000, pp. 359-363.

41 Nó $\varsigma$ es un término que designa a las almas en un estado anterior a la existencia en el mundo material que conocemos.

42 P. Ciner, «Una relectura del De Principiis a la luz del Comentario al Evangelio de Juan. La cuestión de la preexistencia», Teología y Vida 55/2 (2014) pp.275-276. 
aquellos que fueron capaces de recibir en ellos al Logos como Dios. ${ }^{43}$

El planteo de Orígenes consiste en mostrar que esta eternidad del principio convive ciertamente con la dimensión material sujeta al tiempo y al espacio, ${ }^{44}$ además de dar cuenta de un determinado carácter antropológico, ínsito en esta concepción.

Todas las criaturas que devinieron ángeles, hombres y demonios, estaban al principio absorbidas en la contemplación de Dios, en el $\Delta$ ó $\sigma_{\zeta}$, Orígenes ha preferido llamar a estos seres primigenios inteligencias antes que almas. ${ }^{45}$ Estas inteligencias son los vó $\varsigma$, , creaturas espirituales, o el hombre interior -en el caso de los que adoptaron la forma humana de existencia en el mundo material-, mencionado más arriba. De este modo, según este pensamiento, un número definido de seres espirituales incorpóreos, o naturalezas espirituales libres, fue creado al principio, todos originariamente semejantes entre ellos. Así, la diversidad en la creación surgió como consecuencia de las opciones que tuvieron estas naturalezas para escoger una forma corpórea determinada; fueron creadas con la posibilidad de que libremente pudieran conocer y adherirse a Dios, su único bien. Poseían libre albedrío, como un atributo inseparable de su existencia, con lo cual sus decisiones morales no fueron uniformes, en virtud de las que merecieron recibir unos cuerpos u otros. Sólo el uso de su libertad introdujo las desigualdades entre ellos. Para este propósito hizo Dios el mundo material, que tuvo un comienzo en el tiempo; este mundo, donde cada cual nace según los méritos o deméritos de su existencia espiritual,

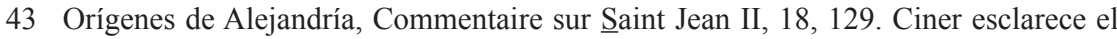
sentido de la palabra mal traducida como «preexistencia», aludiendo a la referencia original griega, en la nota 8 al pie de página de su trabajo inédito: «La doctrina del alma en el Comentario al Evangelio de Juan de Orígenes: sus implicancias en el problema Tiempo-Eternidad». Aquí, destaca lo siguiente: «...el verbo que Orígenes utiliza en este fragmento al referirse al Logos que está desde el principio en el alma es $\pi \rho$ oü $\alpha \dot{\alpha} \rho \chi \omega$. Éste era también el verbo utilizado en los textos condenados por el Concilio de Constantinopla. Este verbo está formado por las preposi-

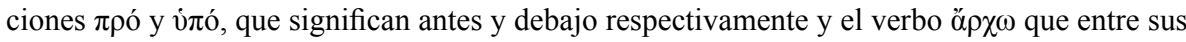
múltiples significaciones puede ser traducido como dar origen, comenzar, preceder, ser la causa de, etc. Si Unimos todos los matices de este complejo y hermoso verbo y lo aplicamos a la obra de Orígenes en donde lo que 'da origen' hace alusión a la sabiduría eterna de Dios y de su Hijo, creemos que debe ser entendido como 'la eternidad del principio que está antes del tiempo y subyace en él.'» Cf. También: P. Ciner, «Una relectura del De Principiis a la luz del Comentario al Evangelio de Juan. La cuestión de la preexistencia», p. 276.

44 Cf. P. Ciner, «Orígenes de Alejandría y el paradigma de la espiritualidad del desierto», Acta Scientiarum 35/1 (2013), p.3.

45 H. Crouzel, Origène, p. 269 
se manifiesta, por tanto, como «un juicio antes del juicio final» y «la historia del mundo es el juicio del mundo». ${ }^{46}$

Así se explica la infinita diversidad que se ve en el mundo, sin que se pueda responsabilizar al destino o a Dios, pues esta manifestación ha sido el resultado del ejercicio del libre albedrío de las criaturas espirituales. A la vez, la creación de este mundo se presenta también como una prueba de la misericordia divina y un acto de condescendencia con las criaturas, a fin de que tuvieran un ser eterno que pudiera retornar a su fuente. ${ }^{47}$

A partir de esta doctrina se entiende que existe una realidad que permanece idéntica a lo largo de la eternidad (el alma celestial), previa y subyacente a la dimensión espacio-temporal y que, por lo tanto, no pierde jamás el contacto directo con lo divino, independientemente del estadío ontológico alcanzado por la libertad en tanto hombre, ángel o demonio, luego de la caída.

\section{DE LA PREEXISTENCIA HACIA LA RESTAURACIÓN FINAL}

Lo antedicho nos ha permitido advertir que el alma celestial es el núcleo preexistente, que, luego de la caída original, ha llegado a ser una unidad con el cuerpo y alma terrenal. En el punto siguiente aludiremos a su conexión con la muerte y la fase final de la existencia humana.

\section{II.1. PREeXISTENCIA Y EXISTENCIA LUEGO DE LA MUERTE}

Orígenes comienza el Libro II de De Principiis refiriéndose al mundo sensible y terrestre, que ha sido el objeto de una suerte de segunda creación, que contiene los seres inanimados, los vegetales y los animados. En medio de este ámbito, viene el hombre a morar, habiendo devenido terrestre, porque el cuerpo etéreo de la preexistencia ha sido revestido por el cuerpo terrenal.

Así, se ve una coherencia de argumentación origeniana en cuanto la materia del mundo creado no es increada, aunque en esta concepción de pensamiento subyace una idea de materia que proviene de la filosofía griega. La materia de la que el mundo se compone es un sustrato amorfo, capaz de recibir diversas cualidades, pero, a diferencia de los pensadores griegos, Orígenes se rehúsa a admitir que la materia no haya tenido un comienzo en el tiempo, ya que ella fue creada a partir de la nada. ${ }^{48}$ Esta concepción de la materia junto a las cualidades que la informan, explica no solamente los cambios que se van produciendo en ella, sino también como expresa H. Crouzel: «l'identité etl'altérité qui existent entre le corps éthéré de la préexistence et le corps

46 R. Seeberg, Manual de historia de las doctrinas I, 2a ed. CPB: El Paso, 1967, p. 158.

47 A. Ropero (compilador y comentador), Lo mejor de Orígenes. Tratado de los Principios. Barcelona: Editorial Clie, 2002, p. 35.

48 Orígenes de Alejandría, De Principiis, II, 1, 4; IV, 4, 6-7. 
terrestre, ainsi que, comme nous le verrons plus loin, entre le corps terrestre et le corps ressuscité.») ${ }^{49}$

Luego de que el hombre ha realizado su vida en la tierra, se produce una transformación del cuerpo corruptible en incorruptible, deviniendo el cuerpo de resurrección. Así, según este pasaje, señala en De Principiis II, 10, 3 que el cuerpo que adviene luego de la muerte física cambiará: será un cuerpo glorificado que será idéntico y diferente a la vez. En la base de la concepción origeniana del cuerpo resucitado se encuentra la comparación, que aparece en 1 Co. 15, 12-58, entre el grano y la planta: así como entre ellos hay una continuidad, pero también una diferencia, así también ocurre con el cuerpo terrestre y el cuerpo glorioso. De este modo, lo que es sembrado en debilidad, surgirá en poder, y, como se dice en 1 Co. 15, 51, todos seremos transformados. ${ }^{50}$

De hecho, debemos pensar que nuestros cuerpos también caerán al suelo como el grano. Pero hay en ellos una razón que mantiene unida la sustancia corporal; aunque los cuerpos están muertos, corruptos y dispersos, esta misma razón que todavía está intacta en la sustancia del cuerpo, por la acción de la Palabra de Dios, levantará estos cuerpos de la tierra, los reconstituirá, los restaurará, del mismo modo que la fuerza que está en el grano de trigo, después de su corrupción y de su muerte, restaura y reconstituye el grano en el cuerpo de la paja y la espiga. ${ }^{51}$

Esta resurrección debe ocurrir en algo, en una realidad que subyace. De este modo, ese ser de la preexistencia, que ha devenido persona humana, al fallecer, pervive en un nuevo cuerpo, el de resurrección, al modo de un revestimiento nuevo y glorioso. Es importante mencionar que Orígenes no habla de reencarnación. Las almas no entran en los cuerpos por transmigración. Él mismo se opuso a la creencia en la reencarnación, mantenida por muchos de sus contemporáneos. «No decimos en absoluto -escribe- que se dé la transmigración del alma, ni que ésta caiga en animales irracionales». ${ }^{52} \mathrm{El}$ texto de Orígenes critica la idea de vidas anteriores en cuerpos de animales y aves, ya que esta idea comprometería seriamente el valor de la santidad y del

49 H. Crouzel, Origène, p. 279.

50 Orígenes de Alejandría, De Principiis, II, 10, 3.

51 Orígenes de Alejandría, De Principiis, II, 10, 3: «Il faut en effet penser que nos corps aussi tomberont en terre comme le grain. Mais il y a en eux une raison qui maintient unie la substance corporelle; bien que les corps soient morts, corrompus et dispersés, cette raison ellemême qui est toujurs intacte dans la substance du corps, par l'action de la Parole de Dieu, relèvera ces corps de la terre, les reconstituera, les restaurera, de même que la force qui est dans le grain de blé, après sa corruption et sa mort, restaure et reconstitue le grain dans le corps de la paille et de l'épi.» Traducción propia.

52 Orígenes de Alejandría, Contra Celso, VIII, 30, y también en Principios I, 8,4 
martirio. Pero considera que la diferencia de méritos motivaron a Dios a crear un mundo hecho de la variedad correspondiente a la diversidad de las caídas de los vó $\varepsilon .{ }^{53}$

Las almas conversas, salvas por el sacrificio de Cristo y purificadas por la fe y santidad del Espíritu, entran al paraíso después de la muerte, que es una especie de escuela de almas, o, como lo llama «mansiones de los aventurados», pues la instrucción y la purificación moral nunca terminan. Este cuerpo espiritual de resurrección es el que será liberado de la esclavitud de la corrupción, no solamente en las almas más puras, sino también en todas las creaturas:

Hasta donde nuestra inteligencia puede entender, creemos que la cualidad de un cuerpo espiritual no sólo debe permitir que las almas santas y perfectas lo habiten, sino también todas aquellas criaturas que serán liberadas de la esclavitud de la corrupción. De este cuerpo, el Apóstol también dice que tenemos una morada no hecha por manos humanas, eterna en el cielo $(2$ Co. 5,1$)$, es decir, en las mansiones de los bienaventurados. De esto podemos conjeturar la pureza, la sutileza y la gloria que serán las cualidades de este cuerpo. ${ }^{54}$

Las almas impías, sin embargo, entran en el infierno, que es el fuego del juicio, una llama de nuestro propio fuego, que se alimenta de la propia pecaminosidad del individuo, torturado por su conciencia. Así, Orígenes destaca lo que el profeta Isaías había afirmado (Is. 50, 11): «id a la lumbre de vuestro propio fuego, y a las brasas que habéis encendido». Cada pecador no es arrojado en algún fuego que haya sido encendido por otro, o que existía antes que él mismo, sino que el combustible y el alimento del fuego son los pecados de cada uno, llamados por el apóstol Pablo «Madera, heno y hojarasca» (1 Co. $3,12){ }^{55}$

Pero no se trata de un castigo permanente, sino un proceso de purificación: «Le agrada al Dios bueno destruir la maldad por el fuego de los castigos. Mientras los malos y los pecadores son así purificados, los buenos se elevan de esfera en esfera para encontrarse con Cristo.» ${ }^{56}$

53 U. Bianchi, «L'anima in Origene e la questione della metensomatosi», Agustinianum 26 (1997) p. 48. 33-50. Aquí se refiere a lo tratado por Orígenes en De Principiis I, 8, 2.

54 Orígenes de Alejandría, De Principiis, III, 6, 4: «Autant que notre intelligence peut le comprendre, nous pensons que la qualité d'un corps spirituel doit permettre non seulement aux âmes saintes et pairfaites de l'habiter, mais encoré à toutes ces créatures qui seront libérées de la servitude de la corruption. De ce corps l'Apotre dit aussi que nous avons une maison non faite de main d'homme, éternelle dans le cieux (2 Co. 5, 1), c'est-à-dire dans les demeures des bienheureux. De cela nous pouvons conjeturer la pureté, la subtilité et la gloire qui seront les qualités de ce corps...» Traducción propia.

55 Cf. Orígenes de Alejandría, De Principiis, II, 10,4.

56 Cf. Orígenes de Alejandría, De Principiis, III, 6, 6. 


\section{II.2. EL CAMINO DEL HOMBRE INTERIOR HACIA LA RESTAURACIÓN FINAL O APOCATÁSTASIS}

Expresa el teólogo que tanto unos como otros llegarán finalmente a la meta de la unión con Dios, aunque sea después de infinitas edades. Luego, con la segunda venida de Cristo, llegará el fin y ocurrirá la resurrección de los cuerpos de los hombres, cuerpos espirituales y gloriosos. Dios será entonces todo en todos y todas las cosas creadas vivirán en la plena visión de la divinidad.

Su total oposición a cualquier tipo de dualismo llevó a Orígenes a negar entidad verdaderamente independiente al mal, que es incompatible con el dominio absoluto del Bien. En De Principiis expone que Dios será «todas las cosas en todos» $(1$ Co. 15,28$)$, ya que Él será todo en cada persona individual y en cada ser:

[...] toda esa inteligencia razonable, purificada de toda la impureza de los vicios y completamente limpia de todas las nubes de la malicia, puede sentir, comprender y creer todo lo que será Dios, y ella no hará nada más que sentir a Dios, pensar en Dios, ver a Dios, tener a Dios, Dios será todos sus movimientos: y así es como Dios será todo. ${ }^{57}$

Dios será todo porque entonces no habrá distinción entre el bien y el mal; el mal ya no existirá en ninguna parte, porque Dios estará en todo. Así, cuando el fin haya restaurado el principio, y la terminación de las cosas sea similar a su comienzo, la condición de la naturaleza racional retornará a su dimensión de eternidad. De este modo, cuando no haya necesidad de comer el fruto del árbol del conocimiento del bien y del mal, cuando todo sentimiento de malicia sea quitado, y el individuo se encuentre purificado y limpio, se dará el retorno de toda la creación a su condición primordial de unidad con Dios; esto ocurrirá no sólo en el caso de unos pocos individuos, sino de un número considerable. ${ }^{58}$

Para Henri Crouzel la posibilidad de conversión de los demonios no aparece en Orígenes con tanta claridad. Los demonios no son malos por naturaleza, sino que se han hecho malos por opción de su libre albedrío.

57 Orígenes de Alejandría, De Principiis, III, 6, 3: «...tout ce qu'une intelligence raisonnable, purifiée de toutes les ordures des vices et nettoyée complètement de tous les nuages de la malice, peut sentir, comprendre et croire tout cela sera Dieu, et elle ne fera rien d'autre que sentir Dieu, penser Dieu, voir Dieu, tenir Dieu, Dieu sera tous ses movements: et c'est ainsi que Dieu lui sera tout.» Traducción propia.

58 Cf. Orígenes de Alejandría, De Principiis, III, 6, 3. 
Debido a su malicia inveterada, el hábito de la maldad puede bloquear el libre albedrío y hacer imposible su conversión a Dios. ${ }^{59}$

En De Principiis habla explícitamente de este retorno de todas las cosas a su fuente. Toda sustancia corporal será recuperada, y todas las cosas restablecidas en un estado de unidad; estado que no ha de suceder de repente, sino que se llevará a cabo mediante estadíos sucesivos, gradualmente, a lo largo de un tiempo innumerable. Todos los seres irán avanzando y reconciliándose con Dios, del que habían sido antes enemigos, y finalmente llegará el turno del último enemigo, llamado muerte, que será destruido: «Cuando todas las almas razonables hayan sido restauradas a este estado, entonces la naturaleza de nuestro cuerpo aquí también será conducida a la gloria del cuerpo espiritual.» ${ }^{60}$ Todas las almas serán transmutadas en la gloria de un cuerpo espiritual, todas las almas pecadoras serán reconciliadas con Dios. Y será el mismo cuerpo, del que ahora hacemos uso en un estado de corrupción y debilidad, transmutado en una condición de gloria, para que sea depurado como vaso de honor y morada de la felicidad.

El $\Delta$ ó $\gamma o \zeta$ es alfa y omega, es el principio y el fin de todas las cosas. Es claro que para este insigne exégeta de las Escrituras, esta idea de retorno de todas las cosas hacia Él constituyó un punto clave en su análisis soteriológico. ${ }^{61}$ Orígenes fue el primero en ver en el hecho histórico de la redención el destino de la humanidad entera, que, caída antes de ingresar en este mundo, debe volver a ella. Siguiendo las palabras de Abbagnano: «Por primera vez se ha reunido en una única visión de conjunto la suerte de la humanidad y la suerte del mundo, haciendo de la antropología cristiana el elemento de su concepción cosmológica. Por primera vez, en fin, se ha afirmado enérgicamente la exigencia de la libertad humana, que se había perdido no sólo en las doctrinas dualistas de los gnósticos, sino también en todas aquellas interpretaciones que hacían del hombre el sujeto pasivo de la obra redentora de Cristo.» 62

59 H. Crouzel, Origène, cap. XIII.

60 Orígenes de Alejandría, De Principiis, III, 6, 6: «Lorsque toutes les âmes raisonnables auront été rétablies en cet état, alors la nature de notre corps que voici sera elle aussi menée a la gloire du corps spirituel.» Traducción propia.

61 Cf. T. Greggs, Barth, Origen and universal salvation. Restoring particularity. Oxford: Oxford University Press, 2009, p. 54.

62 N. Abbagnano, Historia de la filosofía, Volumen 1, «Orígenes». Barcelona: Hora, 1994, p.259. 


\section{VALORACIONES FINALES}

Manlio Simonetti ha descripto de modo muy cabal el carácter de Orígenes, la situación que le llevó a su condena y sus consecuencias, explicitando el valor de la totalidad de su pensamiento; en efecto sostiene:

A noi più che i detagli di questa poco edificante vicenda interessa il suo spirito: Origene con suo libero discutere lasciando spesso aperti i risultati e con l'ampiezza della sua apertura alla cultura greca incarnava un certo modo di sentire la religione cristiana: stretta adesione ai dati fondamentali del deposito di fede a all'autorità della gerarchia, ma anche ampiezza d'idee, fiducia nella discusione condotta ad alto livello, convinzione che il cristianesimo non dovesse temere il dialogo con la filosofía greca, pur di approfondire i suoi contenuti; in una parola, nella sua professione di fede Origene si sente libero, alla maniera di Paolo. Ma proprio questo modo di vivere l'esperienza cristiana é diventato incomprensibile ad Epifanio e a quanti, come lui, respirano quel clima di crescente intolleranza: per loro il cristianesimo é sopratutto autorità, rifiuto della discussione, miopia intelletuale, incapacità di ricercare con libertà di spirito. É fuor di dubbio che il diffondersi di tale modo di vivere il cristianesimo determinava la chiusura più radicale nei confronti di quella formazione ispirata ai princìi della paideia greca, che i Cappadoci, eredi spirituale di Origene nel IV secolo, avevano vagheggiato; e più in generale inardiva ogni possibilità di operare in modo intellettualmente, e perciò culturalmente valido. Il trionfo dell'intolleranza significò trionfo dell'oscurantismo. ${ }^{63}$

Es evidente que Orígenes fue amplio en la apertura del pensamiento cristiano, incluyendo en sus consideraciones elementos de la sabiduría antigua, y de la filosofía griega, y con una estricta adhesión a los datos de la Revelación, del que fue un fiel exégeta. Realmente parece haber comprendido el modo de vivir la experiencia cristiana, y, comprometido con ella, pudo profundizar en su contenido y desplegar aquellos desarrollos que habían quedado fuera de las consideraciones quizá más controvertidas para la autoridad eclesiástica. Esta intolerancia, como señala Simonetti, significó el relegamiento del desarrollo de estas problemáticas a otros ámbitos, favoreciendo el oscurantismo. Sin embargo, con el tiempo, puede atenderse al valor de sus apreciaciones, que aportan explicaciones con sentido que podrían dar respuesta a los interrogantes del pensamiento de hoy sobre antropología y conocimiento real de lo humano.

A la luz de una visión integral del pensamiento origeniano, atendemos a la importancia puntual de su concepción de preexistencia en completa vinculación con la noción de apocatástasis, ambas ideas centrales para la concepción de hombre. Este último término, recibido por nuestro autor de

63 M. Simonetti, Cristianesimo antico e cultura greca. Città di Castello: Borla, 1990, pp. $98-100$. 
la tradición bíblica, acoge el sentido de la restauración de todos los seres a su condición primera, la que consiste en la filiación perfecta, que brota del tener como única actividad la contemplación y el conocimiento del Padre, por mediación del Hijo, lo que revierte en una unidad perfecta, como es expresado en el Comentario al Evangelio de Juan I, 92-93. De esta manera, se puede advertir que el camino que se inicia con la caída de las criaturas espirituales desde la contemplación de Dios, es decir, la creación del mundo material, tiene un valor pedagógico y encuentra su sentido en la restitución de todos los seres racionales en la contemplación del Padre. Es entonces que todo ser que se manifiesta en la maldad, debe dejar de ser enemigo ${ }^{64}$, pues la maldad que le hace serlo no es por naturaleza (ya que toda naturaleza procede de Dios), sino que tiene que ver con el pecado, que es rechazo de la participación de la vida divina. No hay nada en el Comentario al Evangelio de Juan que afirme la salvación del diablo, pero sí afirma ciertamente que en esta instancia final «no quedará ningún enemigo». ${ }^{65}$

Valoramos, en este punto final del trabajo, las palabras de Fernando Soler en su trabajo «Mística del Logos y contemplación del Padre en Orígenes»:

Entre ambos términos (se refiere a la creación y contemplación como apocatástasis), al inicio y al final de cada uno, encontramos el Logos, 'el que recibe de su Padre bueno bienes, para que cada uno, obteniendo de Jesús los bienes que puede contener, llegue a ser en los bienes' (Clo I, 62). Este pasaje hacer referencia a la mediación salvífica que realiza el Hijo de Dios a través de cada una de sus epínoiai, mediante las que tiene la posibilidad de ser un contenido espiritual e intelectual adecuado a cada ser racional, realizando así su pedagogía salvífica. El fin salvífico de la multiplicidad del Salvador es afirmado explícitamente por nuestro autor en Clo I, 119, donde sostiene que éste deviene 'muchas cosas, quizá todas', recordando que la mayor parte de las epínoiai que

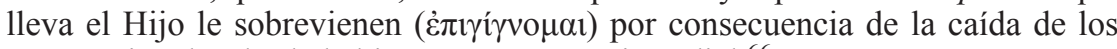
seres racionales desde la bienaventuranza primordial. ${ }^{66}$

\section{REFERENCIAS BIBLIOGRÁFÍCAS}

De Orígenes de Alejandría:

Traité des Principes, en collaboration avec Manlio Simonetti, Tomes I et II, Sources Chrétiennes 252 et 253. Paris: Éditions du Cerf, 1978.

64 Cf. Orígenes de Alejandría, Commentaire sur Saint Jean, I, 91, que debe ser entendido en concordancia con Commentaire sur Saint Jean, XIX, 142.

65 Orígenes de Alejandría, Commentaire sur Saint Jean, I, 91.

66 F. Soler, «Mística del Logos y contemplación del Padre en Orígenes», Teología y Vida 59/4 (2018), p. 513. El contenido del primer paréntesis no aparece en el texto original. 
Traité des Principes, en collaboration avec Manlio Simonetti, Tomes III et IV, Sources Chrétiennes 268 et 269. Paris: Éditions du Cerf, 2008.

Commentaire sur Saint Jean, Texte critique avant-propos, traduction et notes par Cécile Blanc, Tome I, Livres I-V. Paris: Éditions du Cerf, 1966.

Commentaire sur Saint Jean, Texte critique avant-propos, traduction et notes par Cécile Blanc, Tome III, Livre XIII. Paris: Éditions du Cerf, 1975.

Commentaire sur saint Jean, Texte critique avant-propos, traduction et notes par Cécile Blanc, Tome IV, Livres XIX-XX. Paris: Éditions du Cerf, 1982.

Contra Celse, Introduction, texte critique, traduction et notes par Marcel Borret, Tome I, Sources Chrétiennes 132, Paris, Éditions du Cerf, 2005.

Contra Celso. Madrid: BAC, 1967.

Entretien avec Héraclide, Sources Chrétiennes 67. Paris: Éditions Du Cerf, 2002.

General:

ABBAGNANO, N., Historia de la filosofía, Volumen 1, «Orígenes». Barcelona: Hora, 1994.

BATISTTA HARRIET, F., «Tradición platónica acerca de los principios», Diánoia 57/68 (2012) 141-164.

BIANCHI, U., «L'anima in Origene e la questione della metensomatosi», Agustinianum 26 (1997) 33-50.

BLAZQUEZ MARTINEZ, J. M., «Orígenes y su legado al Mundo Antiguo y al Mundo Moderno», Gerión 27/1 (2009) 263-295.

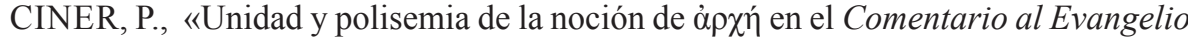
de Juan de Orígenes», Teología y Vida 52/4 (2011) 93-104.

CINER, P., «Orígenes de Alejandría y el paradigma de la espiritualidad del desierto», Acta Scientiarum 35/1 (2013) 1-6.

CINER, P., «Una relectura del De Principiis a la luz del Comentario al Evangelio de Juan. La cuestión de la preexistencia», Teología y Vida 55/2 (2014) 263285.

CROUZEL, H., Origène. Paris: Éditions Lethielleux, 1984.

CROUZEL, H., Orígenes, un teólogo controvertido. Madrid: BAC, 1998.

DANIÉLOU, J., Origène. Paris: Éditions de la Table Ronde, 1948.

FERNÁNDEZ, S., NOEMÍ, J., y POLANCO, R. (comps.), Multifariam. Homenaje a los profesores Anneliese Meis, Antonio Bentué y Sergio Silva, Anales de la Facultad de Teología, 1, Pontificia Universidad Católica de Chile, Santiago, 2010, pp. 193-229.

GREGGS, T., BARTH, Origen and universal salvation. Restoring particularity. Oxford: Oxford University Press, 2009.

LEAL, J., «Las dos almas de la Teología del siglo III: Tertuliano», De anima- Orígenes de Alejandría, De Principiis, Teología y Vida 55/1 (2014) 7-27.

LUND JACOBSEN, A., "Genesis 1-3 as Source for the Anthopology of Origen», Vigiliae Chistianae 62 (2008) 214-232.

MONACI CASTAGNO, A., Origene. Dizionario. La cultura, il pensiero, le opere. Roma: Città Nuova, 2000.

Nueva Biblia de Jerusalén, Desclée de Brouwer, 1998.

ORBE, A., La Epinoia. Roma: Pontificia Universitas Gregoriana, 1955. 
RAMELLI, I., The Christian Doctrine of Apokatastasis: A Critical Assessment from the New Testament to Eriugena. Leiden-Boston: Brill, 2013.

ROPERO, A. (compilador y comentador), Lo mejor de Orígenes. Tratado de los Principios. Barcelona: Editorial Clie, 2002.

SEEBERG, R., Manual de historia de las doctrinas I, 2ª ed. CPB: El Paso, 1967.

SIMONETTI, M., «La controversia origeniana: caratteri e significato», Augustinianum 26 (1986) 7-31.

SIMONETTI, M., Cristianesimo antico e cultura greca. Città di Castello: Borla, 1990.

SOLER, F., «Mística del Logos y contemplación del Padre en Orígenes», Teología y Vida 59/4 (2018) 503-518.

ZAÑARTU, S., «Y el Logos era Dios. Comentario de Orígenes al Evangelio de Juan», Revista Teología 49/108 (2012) 91-100.

Gabriela Caram es profesora de la Universidad Nacional de Cuyo.

Líneas de Investigación:

Ontología y antropología medieval, Filosofía prácticas en su vertiente ética, política, económica, y de la educación

Publicaciones recientes:

(2019). «Tensión hacia Dios y el sentido simbólico de los nombres divinos en Dionisio Areopagita», Universitas Philosophica 36/73, 93-120.

(2017). El argumento de contigüidad ontológica. De la Antigüedad a Tomás de Aquino. Buenos Aires: Teseo (UBA).

Correo electrónico: gabycaram@hotmail.com 